\title{
Follicular development from ovarian xenografts in SCID mice
}

\author{
R. G. Gosden ${ }^{1}$, M. I. Boulton ${ }^{1 *}$, K. Grant ${ }^{1}$ and R. Webb ${ }^{2}$ \\ ${ }^{I}$ Department of Physiology, University Medical School, Teviot Place, Edinburgh EH8 9AG, UK; and \\ ${ }^{2}$ AFRC Roslin Institute (Edinburgh), Roslin, Midlothian EH25 9PS, UK
}

\begin{abstract}
Cortical slices of either cat or sheep ovaries were grafted under the renal capsules of ovariectomized SCID mice. The grafts became vascularized and were still surviving with large follicles present at autopsy up to nine months later. As developing follicles undergo atresia during the period of ischaemia after ovarian grafting, those found in long-term grafts at autopsy had presumably started to grow from the primordial stage after transplantation. Some follicles had reached a diameter of $3 \mathrm{~mm}$ with a normal antrum and appeared to be cytologically normal, but the latent period for the emergence of antral follicles was shorter in cat compared with sheep grafts. Oestradiol production from grafts, as indicated by vaginal cornification and plasma measurements collected at autopsy, was not constant and circulating concentrations varied among animals, and were sometimes far in excess of the normal physiological range of the host. The vaginal smears never presented cytological patterns like those of the normal mouse oestrous cycle, and ovulation had not occurred in any of the grafts. These results demonstrate that ovarian xenografts in SCID mice can serve as experimental models for investigating follicle development in species in which follicle growth in vitro and studies of the parent animal are impracticable.
\end{abstract}

\section{Introduction}

Transplantation of ovaries has been widely used for investigating reproductive biology in small laboratory animals (Krohn, 1977; Gosden, 1992). The small organs and availability of inbred strains in some species have contributed to the successful re-establishment of normal ovarian function in hosts, including hormone secretion, ovulation and fertility. However, when organs are implanted into the host, there is loss of follicles during post-transplantation ischaemia. Nearly all of the developing follicles rapidly disappear as they undergo atresia, and up to $50 \%$ of primordial stages in the cortical region are also lost (Bland and Donovan, 1968; Felicio et al., 1984). This problem can be minimized by anastomosing blood vessels to reduce the period of ischaemia from one or more days to a few minutes (Comier et al., 1985), but the technique is technically demanding and less versatile than simple implants and is impracticable in small laboratory animals. When restoration of fertility is not an experimental aim, it is often advantageous to use ectopic locations such as the subcapsular region of the kidney for ovarian implants. This site is well vascularized and provides a pocket for securing and recovering the graft.

Neither the subcapsular region of the kidney nor the orthotopic site is immunologically privileged and ovarian allografts are aggressively rejected before follicles grow sufficiently large to become secretory and ovulatory ( $R$. G. Gosden and A. A. Murray, unpublished). It is most unlikely that xenografts will survive for longer than allografts. With the

*Present address: The Babraham Institute, Babraham Hall, Cambridge CB2 4AT, UK

Received 2 December 1993. exception of tumour biology, there have been few, if any, attempts to establish ovarian xenografts, although they might provide useful experimental models for investigating follicular development in species, such as humans or large or rare species or breeds, where this is not feasible in situ or in vitro. Knowledge of the physiology of the preantral follicle is mainly confined to a few laboratory species because of practical and ethical obstacles to experimentation with many other species. If the xenograft reaction could be avoided and revascularization encouraged in a common laboratory animal host, follicles might grow when the donor is not closely related to the host. This rests on the assumption that follicles are developmental units requiring only nutrients and pituitary gonadotrophin support from the environment, as indicated by the production of oestrogen and fertile oocytes from follicles cultured in vitro (Eppig, 1992; Gosden et al., 1993). Small follicles, although sensitive to gonadotrophins, do not require FSH and LH for development to proceed to large preantral stages (Dufour et al., 1979; Bamber et al., 1980; Wang and Greenwald, 1993) and, because the biological activities of FSH and LH are not exclusively species specific, it is possible that hormones from the host pituitary gland will support morphogenesis of Graafian follicles and oestrogen production in xenografts.

SCID mice are the most promising models for ovarian xenografting. These mice carry a mutation on chromosome 16 that is responsible for severe combined immunodeficiency which is expressed by agammaglobulinaemia and an absence of mature $B$ and $T$ cells, rendering them tolerant to xenografts (Bosma et al., 1983, 1989). Under barrier conditions, SCID mice remain healthy for up to two years, which is probably sufficiently long for the full span of follicle development of any 
species. The aim of this study was to test the long-term survival of ovarian implants from cats and sheep and to determine whether their follicles will grow in SCID mouse hosts.

\section{Materials and Methods}

\section{Host animals}

The SCID mouse colony was maintained in positive pressure isolators (Moredun, Edinburgh) and screened at intervals of 6 months for serum immunoglobulins (cut-off above $20 \mu \mathrm{g} \mathrm{ml}^{-1}$ ) to maintain the phenotype stringently. The pelleted diet was $\gamma$-irradiated and drinking water was autoclaved and treated 3 days per week and post-operatively with Septrin ( 1 tablet per $600 \mathrm{ml}$, Wellcome, Crewe) as a prophylactic against opportunistic infections.

Fourteen animals were used at approximately 8 weeks of age when they were sexually mature and weighed $25-30 \mathrm{~g}$. Operations were carried out in a laminar flow hood under strictly aseptic conditions. The mice were bilaterally ovariectomized under tribromoethanol anaesthesia $\left(6.03 \mathrm{mg} \mathrm{kg}^{-1}\right.$ body mass) and the left kidney, being the more caudal and accessible of the pair, was exteriorized at a flank incision. A slice of donor ovarian cortex measuring approximately $1.0 \mathrm{~mm} \times 1.0 \mathrm{~mm} \times 0.5 \mathrm{~mm}$ was inserted under the renal capsule with watchmaker forceps. Wounds in the body wall and skin were closed with $7.0 \mathrm{~g}$ suture and Michel clips. The vagina was examined each day for patency and specimens of vaginal cells were collected by lavage during the last $1-2$ weeks before autopsy for examination under the microscope. In a concurrent experiment ovariectomized animals that were age- and sizematched served as controls for organ extirpation and to confirm that there were no external sources of oestrogenic stimulation in the animal house environment.

After a post-operative interval of $1-9$ months, the animals were chosen at random and either killed by cervical dislocation or exsanguinated by cardiac puncture after inducing general anaesthesia with ether. Blood was allowed to clot for 2-4 $\mathrm{h}$ and stored as serum at $-80^{\circ} \mathrm{C}$. Concentrations of oestradiol in serum were measured by radioimmunoassay following an affinity extraction procedure (Webb et al., 1985). The detection limit for this assay was $0.7 \mathrm{pg} \mathrm{ml}^{-1}$ and the mean intraand interassay coefficients of variation were 8.2 and $9.3 \%$, respectively.

At autopsy, complete extirpation of host ovarian tissue was confirmed and the uteri were removed, blotted and weighed. The left kidney was removed for examination and the grafts were dissected. The grafts and corresponding uteri were fixed in $4 \%$ paraformaldehyde, sectioned at $7 \mu \mathrm{m}$ in paraffin wax and stained with haematoxylin and eosin.

\section{Donor tissue}

Grafts were prepared from the ovaries of two cats aged 6-7 months, which were obtained during routine veterinary spaying, and from the ovaries of sheep aged 6-12 months, which were collected either at an abattoir $(n=3)$ or after ovariectomy $(n=9)$. The ovaries were transferred on ice in
Leibovitz-L15 culture medium (Gibco, Paisley) to a sterile cabinet where sections approximately $1 \mathrm{~mm}$ thick were shaved from the cortex with a scalpel. Areas containing large antral follicles or corpora lutea were avoided. Where a risk of infection was suspected, tissues were incubated overnight at $37^{\circ} \mathrm{C}$ in an atmosphere of $5 \% \mathrm{CO}_{2}$ in air in $\alpha$-minimal essential medium containing $10 \%$ donor calf serum (Gibco), gentamicin and amphotericin B (Sigma, Poole). This step in combination with Septrin treatment of the drinking water proved to be effective deterrents and avoided the need to administer antibiotics post-operatively.

\section{Results}

All the animals survived and remained healthy after surgery. The vaginal introitus had closed by 3 days after ovariectomy, as in controls; this indicated that the operations had been successful and that the grafts were not producing oestrogen. This state was permanent in control animals that had been ovariectomized only. The vaginas reopened 3-4 weeks after feline tissue was grafted, whereas a period of 8-20 weeks was required before this occurred with ovine grafts, when the extent of the change was less marked (Fig. 1). Vaginal smears of SCID mice carrying feline grafts became heavily and permanently cornified and the serum concentrations of oestradiol were correspondingly high in both animals at the time of autopsy ( 135 and $317 \mathrm{pg} \mathrm{ml}^{-1}$ ). The uteri of these animals were distended with fluid and, after draining the fluid, each uterus weighed $161 \mathrm{mg}$; histological examination revealed cystic glandular hyperplasia in the endometria. Animals with ovine grafts had fewer comified vaginal cells and lacked uterine distension and hyperplasia. The concentrations of oestradiol in the serum of these animals were correspondingly lower, varying from $105 \mathrm{pg} \mathrm{ml}^{-1}$ to the lower limits of detection (i.e. $<5 \mathrm{pg} \mathrm{ml}^{-1}$ ). Higher concentrations of oestradiol tended to be associated with vaginal opening, but they were not significantly correlated with either the age of the grafts or with uterine masses, which were $117 \pm 22 \mathrm{mg}$ (mean \pm SEM). The results obtained with ovine grafts from different sources were similar.

Ovarian grafts were still discrete many months after surgery and had grown to approximately twice their original size. Follicles of up to $3 \mathrm{~mm}$ diameter, which were visible under the transparent renal capsule, were found in both xenograft species (Fig. 2), but the largest of the ovine follicles were sometimes haemorrhagic. Histology revealed that the grafts had been well-vascularized, with the absence of necrotic tissue (Figs 3 and 4). Clusters of primordial follicles and smaller numbers of growing follicles were present. Although they were not counted, their densities were obviously much lower than in matched tissue that had not been grafted. Morphogenesis of developing follicles and the cytological appearance of granulosa and theca cells and the oocyte were comparable to those of normal tissue. Mitotic figures were observed in granulosa cells, indicating that multilaminar follicles were growing, although some of the later stages contained apoptotic bodies and were probably undergoing atresia. The grafts were evidently anovular because corpora lutea and corpora albicantia were never found. 


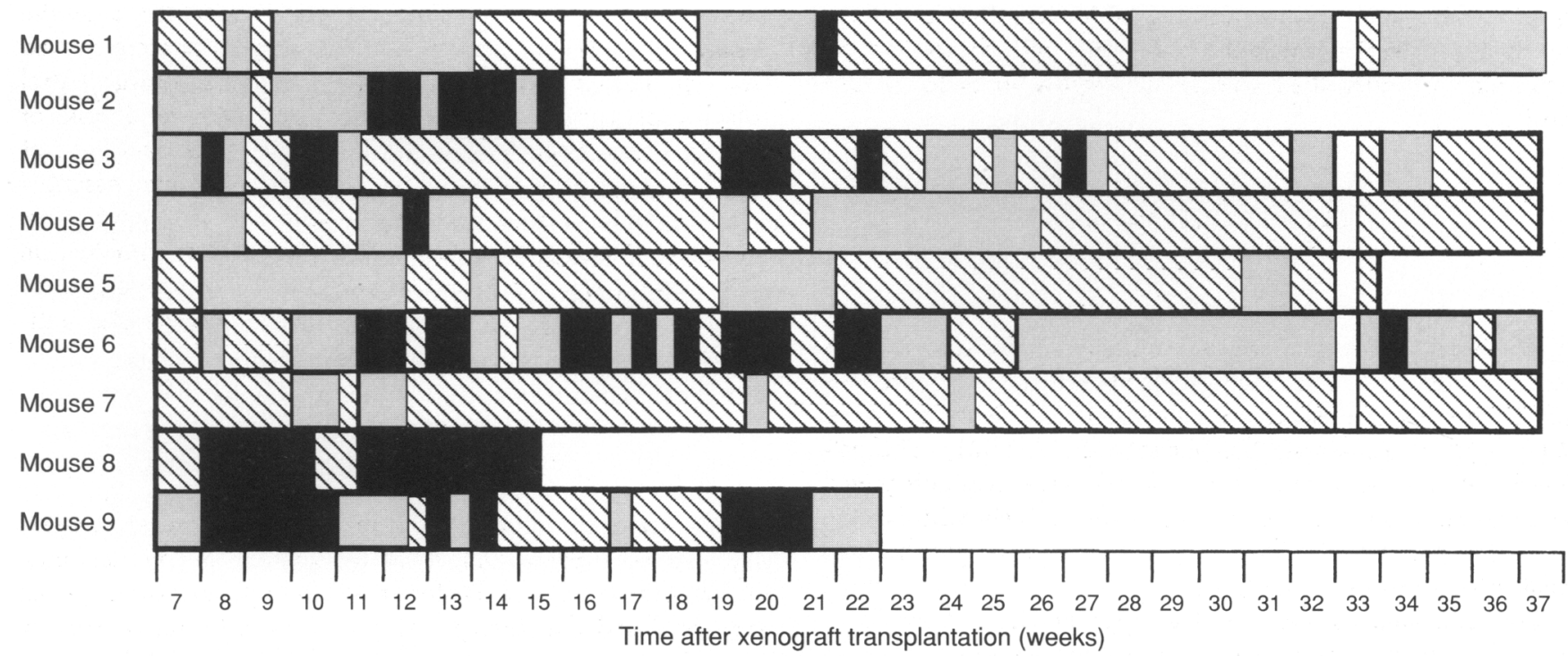

Fig. 1. Vaginal patency of nine SCID mice that were hosts to cortical slices of ovaries from lambs. ( $\mathbf{a}$ ) Vagina fully open; ( $\square$ ) vagina partially open; $(\Delta)$ vagina closed; $(\square)$ a period when no records were collected (week 32). The length of each bar indicates the time of harvesting.

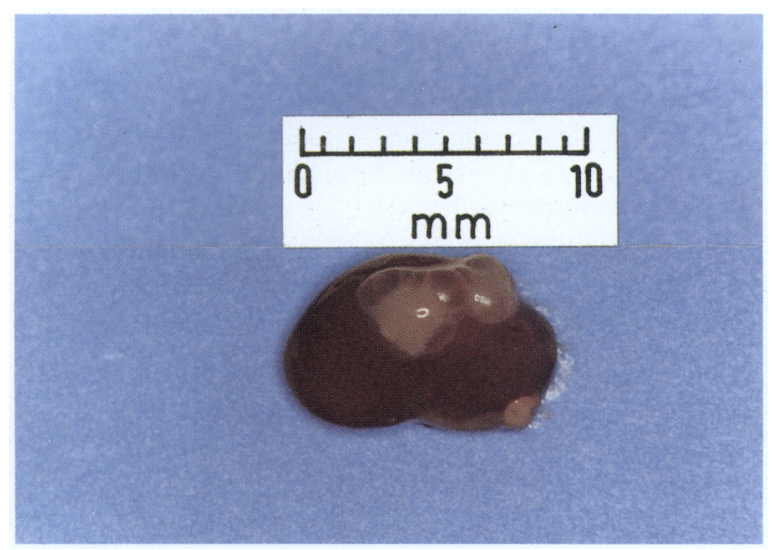

Fig. 2. Feline ovarian tissue nine weeks after grafting under the renal capsule of a SCID mouse. Graafian follicles bulging from the surface measured up to $2 \mathrm{~mm}$ in diameter.

\section{Discussion}

These experiments demonstrate that ovarian xenografts not only survive for many months in SCID mice but also possess follicles developing as far as antral stages. As grafts from two distantly related mammalian orders (Carnivora and Artiodactyla) were successful, we can expect that the model can be applied to a wide range of species.

These studies were intended to test the feasibility of xenografting ovaries rather than providing detailed information about the rates of follicle growth, but they also demonstrated that preantral follicles could grow under these conditions. Primordial follicles evidently survive ovarian implantation better than follicles at later stages, perhaps as a result of a lower metabolic activity (Krohn, 1977). The population of developing follicles found at autopsy was therefore presumably derived from primordial follicles that had been recruited for growth after transplantation. Furthermore, an

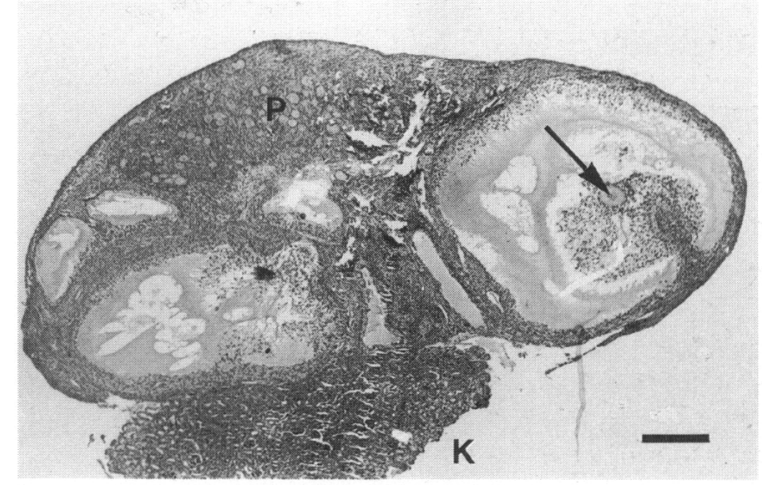

Fig. 3. Histology of the feline graft shown in Fig. 2 with some of the SCID mouse kidney tissue still attached $(\mathrm{K})$. Two large Graafian follicles were present, the cumulus oophorus and oocyte were visible in one of them (arrow). Small antral follicles were also present as well as many primary and primordial follicles in the cortex $(P)$. No luteal tissue was found. (Scale bar represents $1.2 \mathrm{~mm}$.)

indication was obtained of the timespan for primordial follicles to reach the antral stage because vaginal cells are highly sensitive indicators of oestrogen and ovarian tissue is the only significant endogenous source of this hormone. Vaginal patency was not restored until 3-4 weeks in feline-SCID grafts in ovariectomized hosts, whereas ovine grafts required at least twice as long. By contrast external signs of endocrine activity reappear in less than 2 weeks in murine grafts (R. G. Gosden, unpublished). Since the host environment, including gonadotrophic activity, was initially similar for all grafts, we can conclude that the time course of follicle development is mainly determined by the graft rather than the host. On the basis of the limited data available, the time taken for the full development of follicles is species specific, as follows: mouse < cat $<$ sheep. This inference agrees with studies of the kinetics of mouse and sheep follicles in situ (Pedersen, 1970; Cahill and Mauleon, 1980). 


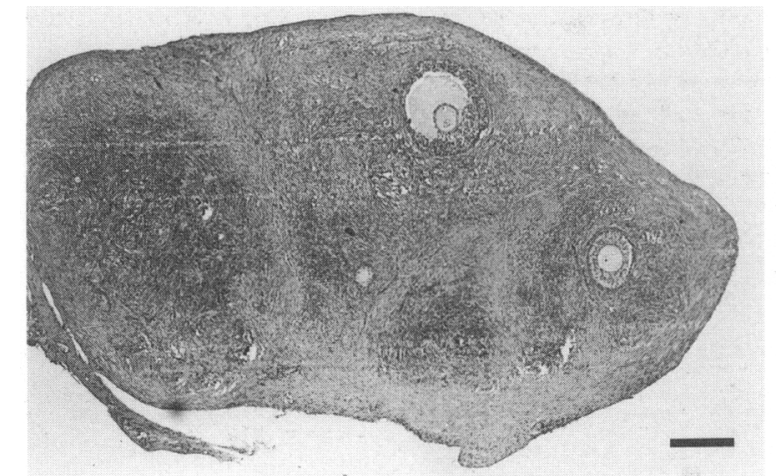

Fig. 4. Histology of an ovine graft 5 months after grafting to the renal capsule of a SCID mouse. The dense mass to the left of centre of the graft had apparently persisted since the operation. Small antral and preantral follicles are growing in an abundant stromal tissue containing a few scattered primordial follicles. (Scale bar represents $1.2 \mathrm{~mm}$.)

There is no reason a priori for expecting that tissues from one species will be well-adapted for functioning in the body of another because the possibility of evolutionary divergence of physiological mechanisms exists. It is therefore remarkable that, on the limited evidence available, development in xenografts was comparable to growth and morphogenesis in the parent species. Moreover, the production of oestrogen and the presence of cytologically normal granulosa cells without apoptotic bodies suggested that the follicles were neither cystic nor atretic.

The concentrations of oestradiol greatly exceeded the normal range of approximately $10-25 \mathrm{pg} \mathrm{ml}^{-1}$ during the mouse oestrous cycle (Nelson et al., 1981), which accounts for heavy cornification of the vaginal epithelium and endometrial hyperplasia with feline grafts. The follicles of this species and of sheep are adapted for secretion into a much larger distribution volume and evidently did not adjust hormone output according to the size and physiology of the SCID mouse. Since oestradiol biosynthesis normally depends on the actions of FSH and LH on granulosa and theca cells, respectively (GoreLangton and Armstrong, 1988), it was presumed that the xenografts were being stimulated by gonadotrophins from the murine pituitary gland. This hypothesis can be tested by experimentally lowering gonadotrophins or by producing host animals which combine mutations for both SCID and hypogonadal (hpg) mice (Cattanach et al., 1977). Animals that are immunodeficient and hypogonadotrophic would be wellcontrolled models for investigating the endocrinology of xenografts.

The second notable departure from normal function was the absence of ovulation, although this was not surprising because ovine follicles (unlike feline) did not reach preovulatory sizes. The termination of development by atresia at the $3 \mathrm{~mm}$ stage, or earlier, might be due to either insufficient gonadotrophic stimulation or to physical restraint by the renal capsule on expanding follicles. Ovine follicles can reach $2-3 \mathrm{~mm}$ in diameter in hypophysectomized ewes (Dufour et al., 1979), suggesting that the SCID mouse may be suitable for the earlier stages of follicular growth, but not during the gonadotrophindependent stages of dominance. In addition, ovine follicles of this size are still 7-14 days short of preovulatory maturity and even peak concentrations of oestradiol are low $\left(<5 \mathrm{pg} \mathrm{ml}^{-1}\right)$ (Scaramuzzi and Land, 1978; Webb and Gauld, 1985). It is for future studies to determine whether circulating $\mathrm{FSH}$ and $\mathrm{LH}$ were inadequate in either concentration or biological activity, but the attainment of supraphysiological concentrations of oestrogen (and probably inhibin) could have caused a vicious cycle leading to eventual suppression of gonadotrophin secretion and atresia by negative feedback.

Ovarian xenografts therefore carry some practical disadvantages insofar as they fail to produce full function, although these differences pose interesting physiological questions in themselves. Their major advantage is in offering the possibility of studying follicle development at all stages from primordial to antral stages using small biopsies of ovarian cortex. A second advantage is the simplicity of the operation, although the quantities of blood that can be repeatedly withdrawn from mice for endocrine studies are limited and SCID mice require specialized husbandry. The xenograft model therefore offers new opportunities for extending knowledge of follicle biology to other species. Moreover, if the problem of atresia in antral follicles can be overcome, it is possible that oocytes could be harvested and contribute to the advancing technology of assisted reproduction for rare breeds and endangered species.

The authors thank the staff of the Medical Microbiology Transgenic Unit for animal husbandry and J. Nicholson for supplying tissue. K. Clark of Ethicon Ltd generously donated Mersilk for surgery. The costs of this research were defrayed by a grant to R. G. Gosden from The Wellcome Trust, funding by OST (EEC) and MAFF to R. Webb and M. I. Boulton gratefully acknowledges a scholarship awarded by the AFRC.

\section{References}

Bamber S, Iddon CA, Charlton HM and Ward BJ (1980) Transplantation of the gonads of hypogonadal (hpg) mice Journal of Reproduction and Fertility $\mathbf{5 8}$ 249-252

Bland KP and Donovan BT (1968) The effect of autotransplantation of the ovaries to the kidneys or uterus on the oestrous cycle of the guinea pig Joumal of Endocrinology 41 95-103

Bosma GC, Custer RP and Bosma MJ (1983) A severe combined immunodeficiency mutation in the mouse Nature $301527-530$

Bosma GC, Davisson MT, Ruetsch NR, Sweet HO, Schultz LD and Bosma MJ (1989) The mouse mutation severe combined immune deficiency (Scid) is on chromosome 16 Immunogenetics $29 \quad 54-57$

Cahill LP and Mauleon P (1980) Influences of season, cycle and breed on follicular growth rates in sheep Journal of Reproduction and Fertility $\mathbf{5 8}$ 321-328

Cattanach BM, Iddon CA, Charlton HM, Chiappa SA and Fink G (1977) Gonadotrophin releasing hormone deficiency in a mutant mouse with hypogonadism Nature $269338-440$

Cornier E, Sibella P and Chatelet F (1985) Études histologiques et devenir fonctionnel des greffes de trompe et d'ovaire chez la ratte (isogreffes et allogreffes traittées par cyclosporine A) Journal de Gynecologie Obstetrique et Biologie de Reproduction (Paris) 14 567-573

Dufour J, Cahill LP and Mauleon P (1979) Short- and long-term effects of hypophysectomy and unilateral ovariectomy on ovarian follicular populations in sheep Journal of Reproduction and Fertility 57 301-309

Eppig JJ (1992) Growth and development of mammalian oocytes in vitro Archives of Pathology and Laboratory Medicine 116 379-382

Felicio LS, Nelson JF, Gosden RG and Finch CE (1984) Restoration of ovulatory cycles by young ovarian grafts in aging mice: potentiation by long-term ovariectomy decreases with age Proceedings of the National Academy of Sciences USA 80 6076-6080 
Gore-Langton RE and Armstrong DT (1988) Follicular steroidogenesis and its control. In The Physiology of Reproduction, Vol. I pp. 331-385 Eds E Knobil and ID Neill. Raven Press, New York

Gosden RG (1992) Transplantation of ovaries and testes. In Fetal Tissue Transplants in Medicine, pp. 253-279 Ed. RG Edwards. Cambridge University Press, Cambridge.

Gosden RG, Boland NI, Spears N, Murray AA, Chapman M, Wade JC, Zohdy N and Brown N (1993) The biology and technology of follicular oocyte development in vitro Reproductive Medicine Review 2 129-152

Krohn PL (1977) Transplantation of the ovary. In The Ovary, Vol. II pp. 101-128 Eds S Zuckerman and BJ Weir. Academic Press, New York and London

Nelson JF, Felicio LS, Osterburg HH and Finch CE (1981) Altered profiles of estradiol and progesterone associated with prolonged estrous cycles and persistent vaginal cornification in aging C57BL/6J mice Biology of Reproduction 24 784-794
Pedersen T (1970) Determination of follicle growth rate in the ovary of the immature mouse Journal of Reproduction and Fertility 21 81-93

Scaramuzzi RJ and Land RB (1978) Oestradiol levels in sheep during the oestrous cycle: a comparison of breeds of different fecundity Journal of Reproduction and Fertility 53 167-171

Wang X-N and Greenwald GS (1993) Hypophysectomy of the cyclic mouse. I. Effects on folliculogenesis, oocyte growth and FSH- and hCG-receptors Biology of Reproduction 48 585-594

Webb R and Gauld IK (1985) Folliculogenesis in sheep: control of ovulation rate. In Genetics of Reproduction in Sheep, pp. 261-274 Eds RB Land and DW Robinson. Butterworths, London

Webb R, Baxter G, McBride D, Nordblom GD and Shaw MPK (1985) The measurement of testosterone and oestradiol-17 $\beta$ using iodinated tracers and incorporating an affinity chromatography extraction procedure Journal of Steroid Biochemistry 23 1043-1051 